\title{
High Pressure DTA Study on the Melting and Crystallization of Poly(E-caprolactone) in a Mixture with Poly(styrene-co-acrylonitrile)
}

\author{
Chitoshi NAKAFUKU \\ Faculty of Education, Kochi University, Kochi 780, Japan
}

(Received February 18, 1989)

\begin{abstract}
The effects of mixing of poly(styrene-co-acrylonitrile) (SAN) on the melting and crystallization process of poly( $\varepsilon$-caprolactone) (PCL) were studied under high pressures up to $500 \mathrm{MPa}$ by high pressure differential thermal analysis (DTA). The pressure coefficient of the melting temperature of PCL crystallized at $0.1 \mathrm{MPa}$ was $0.179 \mathrm{~K} \mathrm{MPa}^{-1}$ and it slightly increased with decreasing PCL content in the mixture. The phase diagram of the binary mixture in terms of melting and crystallization of PCL was determined under high pressure up to $500 \mathrm{MPa}$. The exothermic peak of crystallization of PCL in DTA curve shifts to the low temperature side and becomes broad with increasing SAN content in the mixture and this trend is remarkable at elevated pressure.

KEY WORDS Poly(e-caprolactone) / Poly(styrene-co-acrylonitrile) / High

Pressure / Melting / Crystallization / Differential Thermal Analysis / Phase

Diagram
\end{abstract}

In recent years, many investigations on the compatibility of polymer pair have been reported. Among them, the compatibility of poly( $\varepsilon$-caprolactone) (PCL) and poly(styreneco-acrylonitrile) (SAN) was studied by Chiu and Smith. ${ }^{1,2}$ It was reported that if acrylonitrile (AN) content in SAN is between 8 and $28 \%$, SAN and PCL is compatible and the melting temperature depression of PCL with increasing SAN content in the mixture occurs. Furthermore, continuous change of $T_{\mathrm{g}}$ with weight fraction in the mixture from $190 \mathrm{~K}$ of PCL to $384 \mathrm{~K}$ of SAN was reported by them. Kressler and Kammer reported that a miscibility window of SAN in the blend with PCL exists between 8 and about $30 \%$ in $\mathrm{AN}$ content. $^{3}$

Melting and crystallization behavior of many crystalline polymers under high pressure have been reported in the past two decades. ${ }^{4}$ High pressure phase and the formation of crystalline polymorphs under high pressure have been reported for some crystalline polymers. However, there is no report on such a study under high pressure for PCL.

The effect of pressure on the melting and crystallization of crystalline polymers in the mixture with miscible amorphous polymer was studied recently for poly(vinylidene fluoride) (PVDF) in a mixture with poly(methyl methacrylate (PMMA). ${ }^{5}$ The melting behavior of PVDF under high pressure is complicated because the phase transition from form II to form I which is stable and easily formed under pressure occurs during heating in DTA above about $150 \mathrm{MPa}$. Therefore, the melting phase diagram of PVDF in the binary mixture with PMMA was not determined precisely above $150 \mathrm{MPa}$.

It is the purpose of this paper to study the melting and crystallization behavior of pure PCL and PCL in a compatible mixture with SAN under high pressure. Determination of the phase diagram of melting of PCL in the 
binary mixture under high pressure is also an object of this study.

\section{EXPERIMENTAL}

A PCL sample with a molecular weight of 33000 purchased from Scientific Polymer Products, Inc. was used. SAN with an AN content of $25 \mathrm{wt} \%$ was also purchased from the same company. The mixed pellets of $1 \mathrm{~g}$ of PCL and SAN with a desired weight fraction were dissolved in $30 \mathrm{ml}$ of 1,2-dichloroethane at room temperature in a laboratory dish and the solvent was evaporated at $25^{\circ} \mathrm{C}$ for 2 days. The film sample was completely dried in a vacuum oven at $40^{\circ} \mathrm{C}$. The blend film obtained was cut into small tips and a rod-like sample with $1.8 \mathrm{~mm}$ in diameter was molded in a glass tube at $90^{\circ} \mathrm{C}$.

DTA under high pressure was performed by use of apparatus described elsewhere. ${ }^{6}$ A small pellet-like sample of $1.8 \mathrm{~mm}$ in diameter and $1.8 \mathrm{~mm}$ in length was used in DTA. The heating rate of DTA was $6 \mathrm{~K} \mathrm{~min}^{-1}$ and the cooling rate was about $5 \mathrm{~K} \mathrm{~min}^{-1}$. The melting and crystallization experiment by DTA at $0.1 \mathrm{MPa}$ and under high pressure was performed on the sample crystallized by slow cooling from the fused state $\left(12^{\circ} \mathrm{C} \sim 15^{\circ} \mathrm{C}\right.$ higher than peak melting temperature) at the same cooling rate as that of DTA (about $5 \mathrm{~K} \mathrm{~min}^{-1}$ ).

\section{RESULTS AND DISCUSSION}

The DTA curve of melting at elevated pressure of pure PCL crystallized at atmospheric pressure is shown in Figure 1. The endothermic peak of melting shifted high temperature side with increasing pressure. The shape of the peak in this polymer did not change with pressure, so that a high pressure phase observed in polyethylene under pressure above about $350 \mathrm{MPa}^{6,7}$ did not appear in PCL under high pressures up to $500 \mathrm{MPa}$. Crystalline transformation as appeared in poly(vinylidene fluoride) under high pressure ${ }^{8}$ from the crystal

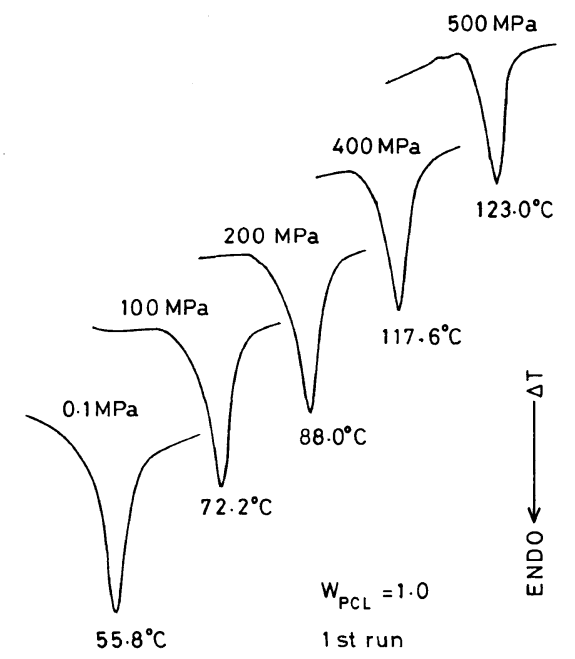

Figure 1. DTA curve of melting of pure PCL crystallized at $0.1 \mathrm{MPa}$ at elevated pressure. Peak temperatures are indicated in the figure.

structure stable at $0.1 \mathrm{MPa}$ (form II) to the other crystalline form (form I) during heating did not occur.

Pressure dependence of the melting temperature $T_{\mathrm{m}}$ and crystallization temperature $T_{\mathrm{c}}$ of pure PCL up to $500 \mathrm{MPa}$ is shown in Figure 2. The melting and crystallization curves $\left(T_{\mathrm{m}}\right.$ and $T_{\mathrm{c}}$ versus pressure) fit the quadratic equation, $T_{\mathrm{m}}=A+B P-C P^{2}$ and the coefficients $A$, $B$ and $C$ are determined by the least squares method. The pressure coefficient of melting temperature $\left(\mathrm{d} T_{\mathrm{m}} / \mathrm{d} P\right)$ determined by the coefficient $(B)$ of $P$ in the quadratic equation was $0.179\left(\mathrm{~K} \mathrm{MPa}^{-1}\right)$ in run 1 of the DTA measurement. The peak temperature of melting in the 2nd run (run 2) in high pressure DTA, of the sample crystallized at the same pressure, shifted to low temperature, so that the pressure coefficient for the peak temperature of run 2 was determined independently. The pressure coefficient for run 2 was 0.173 $\left(\mathrm{K} \mathrm{MPa}^{-1}\right)$. The pressure coefficient of $T_{\mathrm{m}}$ of PCL was very small compared with other polymer crystals for example polyethylene of $0.28\left(\mathrm{~K} \mathrm{MPa}^{-1}\right)$ or polypropylene of 0.366 $\left(\mathrm{K} \mathrm{MPa}^{-1}\right)$ and the value is very close to that of poly(ethylene oxide) (PEO) (0.157 


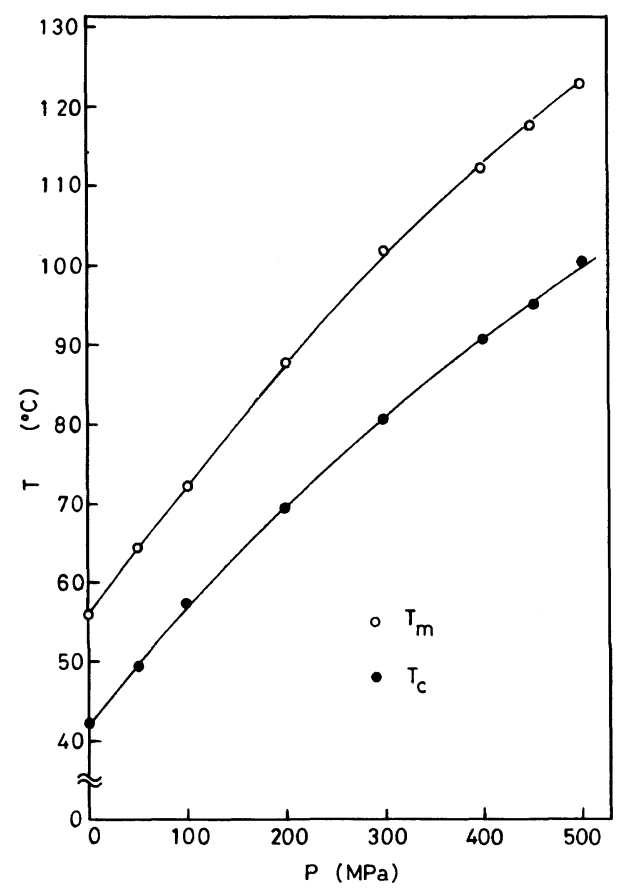

Figure 2. Pressure change of the peak melting temperature $T_{\mathrm{m}}$ and crystallization temperature $T_{\mathrm{c}}$ of pure PCL.

$\mathrm{KMPa}^{-1}$ ). The molecular chains for both PCL and PEO are flexible because both polymers contain oxygen in the main chain and both polymer crystals show lower melting temperatures and smaller $\mathrm{d} T_{\mathrm{m}} / \mathrm{d} P$ than the other crystalline polymers.

Figure 3 shows the DTA curve of melting at $0.1 \mathrm{MPa}$ of PCL crystallized at $0.1 \mathrm{MPa}$ in the mixture with different weight fraction. The size of the endothermic peak of melting decreases with decreasing weight fraction of PCL and the peak disappears at the weight fraction of 0.2. The peak temperature position of PCL shifts to the low temperature side with decreasing weight fraction of PCL. In general, $T_{\mathrm{m}}$ of PCL in the mixture with miscible amorphous polymer changes with the crystallization conditions, so that in this study the crystallization was performed by cooling at almost a constant cooling rate as described in the Experimental. The weight fraction dependence of $T_{\mathrm{m}}$ of PCL in the mixture at $0.1 \mathrm{MPa}$ is shown in Figure 4.

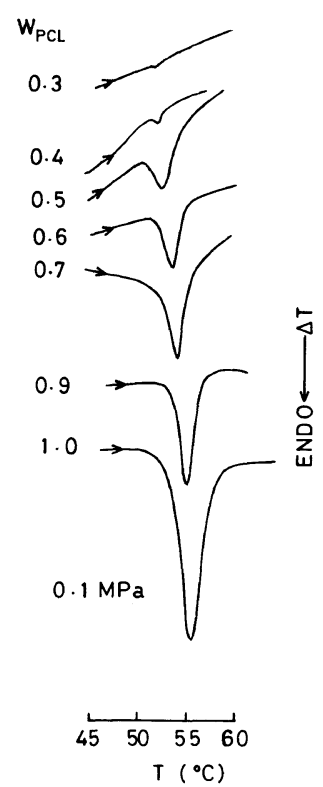

Figure 3. DTA curve of melting of PCL in the blend at $0.1 \mathrm{MPa}$. $W_{\mathrm{PCL}}$ means the weight fraction of PCL in the mixture.

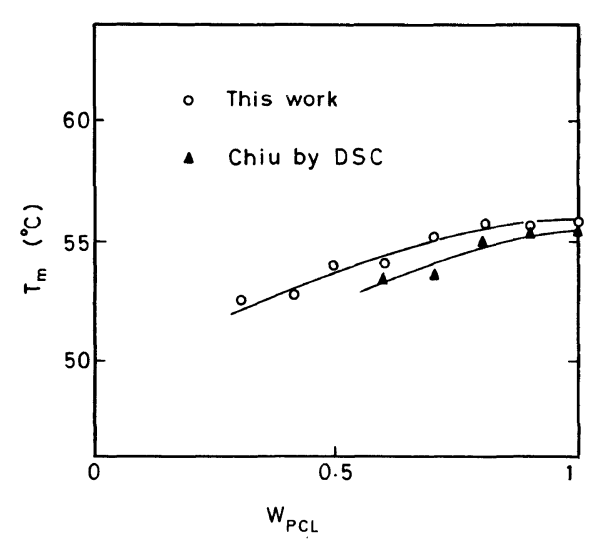

Figure 4. Change of melting temperature of PCL at $0.1 \mathrm{MPa}$ as a function of $W_{\mathrm{PCL}}$. $\mathrm{O}$, this work; $\mathbf{\Delta}$, by Chiu. ${ }^{1}$

$T_{\mathrm{m}}$ of PCL decreases with decreasing weight fraction of PCL. This trend almost corresponds to that of $T_{\mathrm{m}}$ of PCL obtained by Chiu. ${ }^{1}$

Figure 5 shows the DTA curve of melting of PCL in the mixture of the weight fraction 0.6 at elevated pressures up to $500 \mathrm{MPa}$. The endothermic peak of melting of PCL in the mixture only shifts to the high temperature 


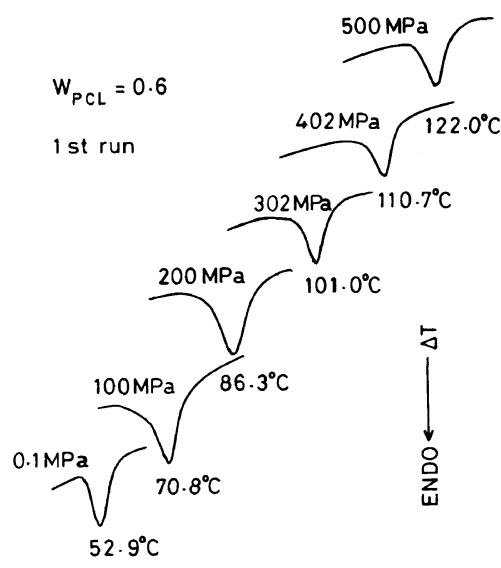

Figure 5. DTA curve of melting of PCL in the mixture of $W_{\mathrm{PCL}}=0.6$ at elevated pressure.

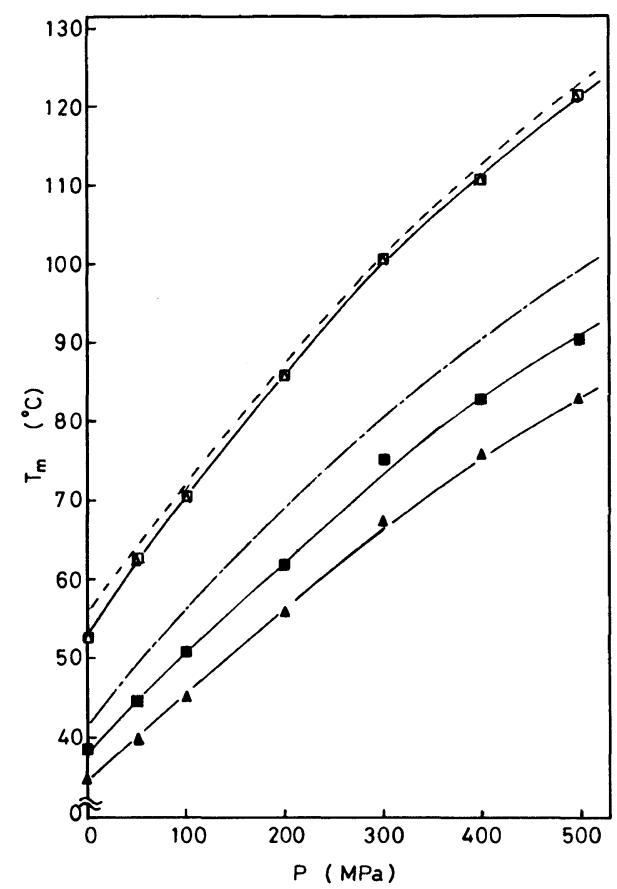

Figure 6. Pressure dependence of $T_{\mathrm{m}}$ and $T_{\mathrm{c}}$ of PCL in the mixture of $W_{\mathrm{PCL}}=0.6$ and 0.5 . . . - melting of pure PCL; $\square$, melting of $W_{\mathrm{PCL}}=0.6 ; \triangle$, melting of $W_{\mathrm{PCL}}=$ 0.5 ; _ - - ; crystallization of pure PCL; $\square$, crystallization of $W_{\mathrm{PCL}}=0.6 ; \Delta$, crystallization of $W_{\mathrm{PCL}}=0.5$.

side with pressure but the shape of the peak does not change as observed in the case of pure PCL. The peak temperatures of melting and crystallization of PCL in the mixture of
Table I. $A, B$, and $C$ in the equation, $T_{\mathrm{m}}=A+B P-C P^{2}$ for the melting temperature of PCL in the mixture with different weight fractions in run 1 in DTA

\begin{tabular}{|c|c|c|c|}
\hline \multirow{2}{*}{$W_{\mathrm{PCL}}$} & $A$ & $B$ & $C$ \\
\hline & $\mathbf{K}$ & $\mathrm{K} \mathrm{MPa}^{-1}$ & $\mathrm{~K} \mathrm{MPa}^{-2}$ \\
\hline 1.0 & 55.7 & 0.179 & $9.09 \times 10^{-5}$ \\
\hline 0.9 & 55.8 & 0.182 & $9.94 \times 10^{-5}$ \\
\hline 0.8 & 55.6 & 0.175 & $8.34 \times 10^{-5}$ \\
\hline 0.7 & 55.5 & 0.181 & $9.46 \times 10^{-5}$ \\
\hline 0.6 & 53.4 & 0.185 & $9.86 \times 10^{-5}$ \\
\hline 0.5 & 53.5 & 0.184 & $10.10 \times 10^{-5}$ \\
\hline $0.4^{\mathrm{a}}$ & 52.7 & 0.202 & $15.27 \times 10^{-5}$ \\
\hline
\end{tabular}

${ }^{\text {a }}$ For $W_{\mathrm{PCL}}=0.4$, the coefficients were determined by using the data up to $300 \mathrm{MPa}$.

$W_{\mathrm{PCL}}=0.6$ and 0.5 were plotted against pressure in Figure 6. In the figure, the melting curve of PCL in the mixture slightly shifts to the low temperature side with increasing weight fraction of SAN. The melting curve of PCL for run 1 of DTA in the mixture with different weight fractions also fit the quadratic equation and the coefficients are listed in Table I. In the case of $W_{\mathrm{PCL}}=0.4$, the melting peak disappears above $400 \mathrm{MPa}$, so that the curve fitting was performed for the data up to $300 \mathrm{MPa}$. It is recognized that $T_{\mathrm{m}}$ of PCL decreases with decreasing weight fraction of PCL but it seems that $\mathrm{d} T_{\mathrm{m}} / \mathrm{d} P$ increases very slightly with decreasing weight fraction of PCL.

The crystallization curve shifts to the low temperature side much more than the shifting of $T_{\mathrm{m}}$ with decreasing weight fraction of PCL as shown in the figure. The peak temperature difference for $W_{\mathrm{PCL}}=1.0$ and 0.6 at $500 \mathrm{MPa}$ for crystallization is $8.8 \mathrm{~K}$ which is much larger than the difference for the melting (1.2 $\mathrm{K}$ in difference). The values of $A^{\prime}\left(T_{\mathrm{c}}\right), B^{\prime}$ $\left(\mathrm{d} T_{\mathrm{c}} / \mathrm{d} P\right)$ and $C^{\prime}$ in the quadratic equation for the crystallization temperature $T_{\mathrm{c}}$ are listed in Table II. The hindering effect of the amorphous polymer on the crystallization of crystalline polymer in the binary mixture appears as a 
lowering and broadening of the exothermic peak of crystallization in thermal analysis as reported by Nishi and Wang on the crystallization of PVDF in the mixture with PMMA. ${ }^{9}$ In the experiment for PCL and SAN mixture, the

Table II. $A^{\prime}, B^{\prime}$, and $C^{\prime}$ in the equation, $T_{\mathrm{c}}=A^{\prime}+$ $B^{\prime} P-C^{\prime} P^{2}$, for the crystallization temperature of PCL in the mixture with different weight fractions in run 1 in DTA

\begin{tabular}{|c|c|c|c|}
\hline \multirow{2}{*}{$W_{\mathrm{PCL}}$} & $A^{\prime}$ & $B^{\prime}$ & $C^{\prime}$ \\
\hline & $\mathbf{K}$ & $\mathrm{KMPa}^{-1}$ & $\mathrm{~K} \mathrm{MPa}^{-2}$ \\
\hline 1.0 & 42.5 & 0.148 & $6.69 \times 10^{-5}$ \\
\hline 0.9 & 40.9 & 0.162 & $8.34 \times 10^{-5}$ \\
\hline 0.8 & 41.8 & 0.159 & $9.23 \times 10^{-5}$ \\
\hline 0.7 & 40.3 & 0.151 & $11.39 \times 10^{-5}$ \\
\hline 0.6 & 37.9 & 0.141 & $6.95 \times 10^{-5}$ \\
\hline $0.5^{\mathrm{a}}$ & 34.8 & - & - \\
\hline
\end{tabular}

a For $W_{\mathrm{PCL}}=0.5$, the exothermic peak of crystallization appears up to only $50 \mathrm{MPa}$.

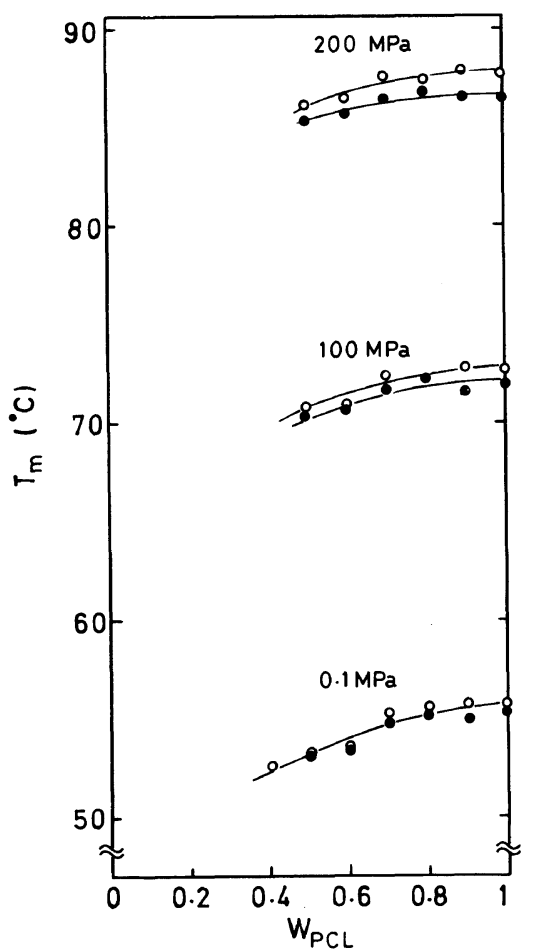

(a) hindering effect of SAN molecule increased with pressure, especially at the low weight fraction of PCL.

The peak melting temperature for run 2 decreased in comparison with the peak tem-

Table III $A, B$, and $C$ in the equation, $T_{\mathrm{m}}=A+$ $B P-C P^{2}$ for the melting temperature of $\mathrm{PCL}$ in the mixture with different weight fractions in run 2 in DTA

\begin{tabular}{|c|c|c|c|}
\hline \multirow{2}{*}{$W_{\mathrm{PCL}}$} & $A$ & $B$ & $C$ \\
\hline & $\mathrm{K}$ & $\mathrm{K} \mathrm{MPa}^{-1}$ & $\mathrm{~K} \mathrm{MPa}^{-2}$ \\
\hline 1.0 & 55.4 & 0.173 & $8.38 \times 10^{-5}$ \\
\hline 0.9 & 55.4 & 0.181 & $9.80 \times 10^{-5}$ \\
\hline 0.8 & 55.5 & 0.180 & $10.24 \times 10^{-5}$ \\
\hline 0.7 & 54.7 & 0.181 & $10.24 \times 10^{-5}$ \\
\hline 0.6 & 53.5 & 0.181 & $9.69 \times 10^{-5}$ \\
\hline $0.5^{\mathrm{a}}$ & 53.2 & 0.187 & $12.92 \times 10^{-5}$ \\
\hline
\end{tabular}

${ }^{\text {a For }} W_{\mathrm{PCL}}=0.4$, the coefficients were determined by using the data up to $300 \mathrm{MPa}$.

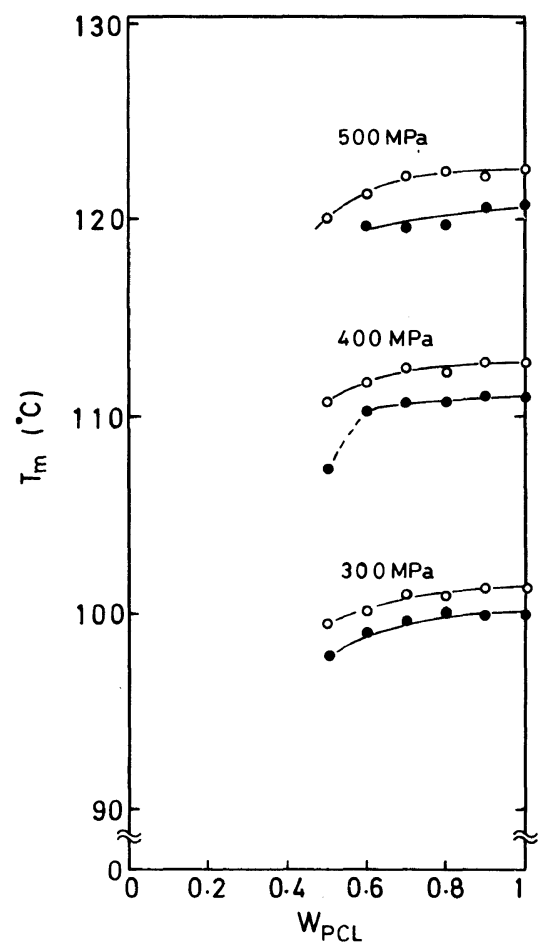

(b)

Figure 7. Pressure change of the phase diagram of melting of PCL in the mixture. (a), $0.1 \mathrm{MPa}, 100 \mathrm{MPa}$, and $200 \mathrm{MPa}$; (b), $300 \mathrm{MPa}, 400 \mathrm{MPa}$, and $500 \mathrm{MPa}$. Data of $T_{\mathrm{m}}$ calculated from the quadratic equation using the values of Tables I and III are plotted. $\bigcirc$, run 1;, run 2. 


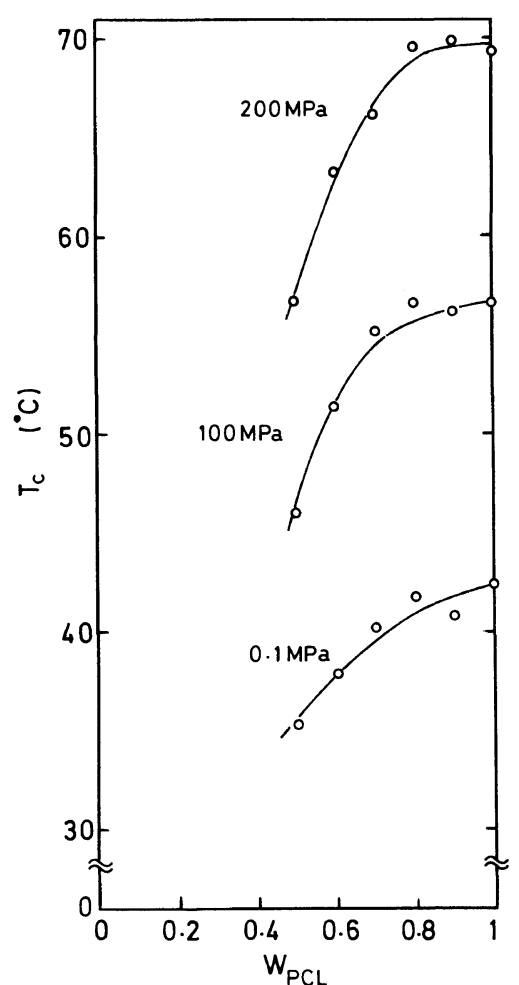

(a)

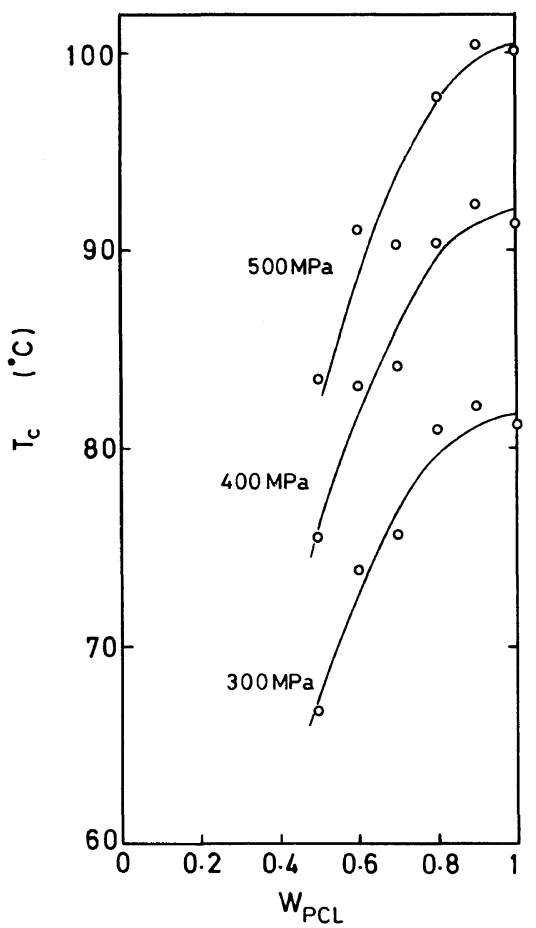

(b)

Figure 8. Pressure change of the phase diagram of crystallization of $P C L$ in the mixture with cooling rate of about $5 \mathrm{~K} \mathrm{~min}^{-1}$. (a), 0.1, 100, $200 \mathrm{MPa}$; (b), 300, 400, $500 \mathrm{MPa}$.

perature for run 1 . This means that $T_{\mathrm{m}}$ of the high pressure crystallized PCL in the mixture decreases so that the effect of SAN to hinder the crystallization of PCL increased at elevated pressure in this mixture. Therefore, $T_{\mathrm{m}}$ versus pressure curve was also obtained for run 2 and the melting curve of PCL is drawn for runs 1 and 2 . The melting curve for run 1 shifts more to the low temperature side than the curve for run 2. Table III lists the calculated values of $A$, $B$, and $C$ for run 2 . The phase diagram of melting of PCL in the binary mixture under pressures up to $500 \mathrm{MPa}$ was obtained by plotting the calculated values of $T_{\mathrm{m}}$ for each $100 \mathrm{MPa}$ as shown in Figures 7(a) and (b). The melting peak of PCL in the mixture of weight fraction of 0.5 did not appear in run 2 at $500 \mathrm{MPa}$, so that the curve at $500 \mathrm{MPa}$ was drawn on the weight fraction range from 1.0 to
0.6. The decreasing rate of $T_{\mathrm{m}}$ with decreasing weight fraction of PCL seems to be unchanged with pressure. At about $500 \mathrm{MPa}$, a drastic decrease of $T_{\mathrm{m}}$ was observed in $W_{\mathrm{PCL}}=0.5$ and as the reason for this decrease of $T_{\mathrm{m}}$, it is considered that imperfect or small crystal of PCL is made in the mixture with such a lower content of PCL. The melting phase diagram of PCL for both run 1 and run 2 in DTA increased with pressure and the interval of the two curves increased with pressure.

Figures 8(a) and (b) show the pressure change of the phase diagram of crystallization of PCL in the mixture. Decreasing rate of $T_{\mathrm{c}}$ of PCL with increasing weight fraction of SAN increases drastically with pressure. It should be reasonably considered that the interference effect of a SAN molecule on the crystallization of PCL increases with pressure. 

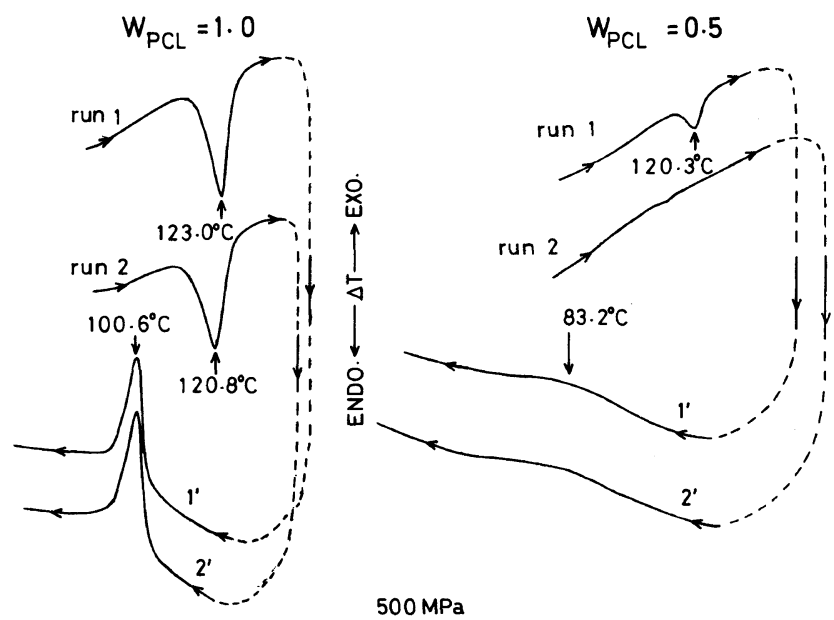

Figure 9. DTA curve of melting and crystallization of pure PCL and PCL in the mixture of $W_{\mathrm{PCL}}=0.5$ at $500 \mathrm{MPa}$. Curve $1^{\prime}$ and $2^{\prime}$ means crystallization after melting of run 1 and run 2, respectively.

The endothermic peak of the melting of PCL disappeared at 0.2 in the weight fraction at $0.1 \mathrm{MPa}$. At elevated pressure, the weight fraction at which the melting peak disappeared shifted to the high PCL fraction side as observed in Figure 7. In the sample of the weight fraction of 0.4 , the melting peak of PCL did not appear at $400 \mathrm{MPa}$ even in run 1. Figure 9 shows the DTA curve of the melting of pure PCL and PCL in the mixture at $500 \mathrm{MPa}$. In pure PCL, sharp endothermic and exothermic peaks appear in the heating and cooling process. But, the melting peak disappeared in run 2 for the weight fraction of 0.5 , in spite of almost the same size of peak as that which appeared at $0.1 \mathrm{MPa}$ was observed at $500 \mathrm{MPa}$ in run 1. The exothermic peak of crystallization became very broad and small and the peak shifted to low temperature side for both run 1 and run 2 at the same pressure for the same sample. Therefore, it is reasonably considered that the effect of SAN molecule to interfere with the crystallization of PCL in the mixture increased with pressure, especially above $400 \mathrm{MPa}$.

\section{REFERENCES}

1. S. Chiu, Doctoral Thesis, University of Maryland, Maryland, 1981.

2. S. Chiu and T. G. Smith, J. Appl. Polym. Sci., 29, 1797 (1984).

3. J. Kressler and H. W. Kammer, Polym. Bull., 19, 283 (1988).

4. B. Wunderlich, "Macromolecular Physics," Vol. 3, Academic Press, New York, N. Y., 1980, Chapter VIII.

5. C. Nakafuku and M. Yasuniwa, Polym. J., 19, 845 (1987).

6. M. Yasuniwa, C. Nakafuku, and T. Takemura, Polym. J., 4, 526 (1973).

7. D. C. Bassett, "Developments in Crystalline Polymers-2," Applied Science Publishers, London, U. K., 1982, Chapter III.

8. K. Matsushige and T. Takemura, J. Polym. Sci., Polym. Phys. Ed., 16, 921 (1978).

9. T. Nishi and T. T. Wang, Macromolecules, 8, 909 (1975). 